\title{
Congenital Anomalies due to Transmission of a Chromosome Translocation
}

\author{
J. E. GRAY, J. A. DARTNALL, R. D. G. CREERY, and J. CROUDACE
}

From the Department of Anatomy, The Medical School, University of Newcastle upon Tyne, and the South Shield and District Hospitals

\section{Case Report}

A boy, born in hospital, was the first-born child of his parents, the father being 21 years old and the mother I9 years. The pregnancy and delivery were uneventful. At birth the child weighed $7 \mathrm{lb}$. I4 oz. ( $3590 \mathrm{~kg}$.). He was noted to have the following abnormalities (Fig. I and 2); a large anterior fontanelle with persistent frontal suture; wide bridge to the nose; small pupils with poor reaction to light; probable blocked tear-ducts; large low-set ears; loose skin around neck; hands flexed with dimple over distal ends of radius; divarication of recti; small exomphalos; small genitalia with undescended right testis; bilateral talipes equinovarus with abducted great toes; retracted nipples; cyanosis; variable systolic heart murmur; and 'clicking' right hip.

Received March 22, 1965.
Clinical Course. The exomphalos was treated successfully by painting with $\mathrm{I} \%$ mercurochrome. The cyanosis continued and from time to time became very severe. Interventricular septal defect was suggested as the likely diagnosis. The child died at $3 \frac{1}{2}$ months of age, following a short terminal illness in which increasing cyanosis and dyspnoea terminated in respiratory failure.

Necropsy (Dr. C. D. Jobling). This confirmed the clinical findings. In addition the lungs showed partial atelectasis in the right lung and the lower lobe of the left lung. Haemorrhage had occurred in the middle lobe of the right lung and lower lobe of the left lung. There was black material in the air passages and stomach. The heart showed (i) enormous hypertrophy of the right ventricle, (ii) common truncus arteriosus giving off

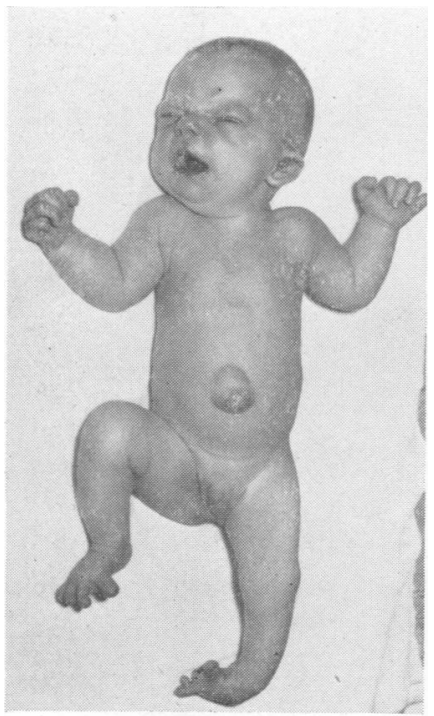

FIG. I. The propositus at I month.

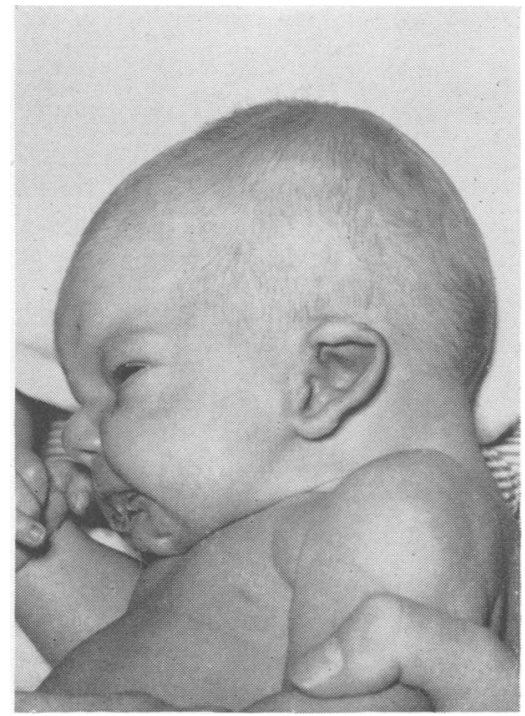

Fig. 2. Head of the propositus at I month. 


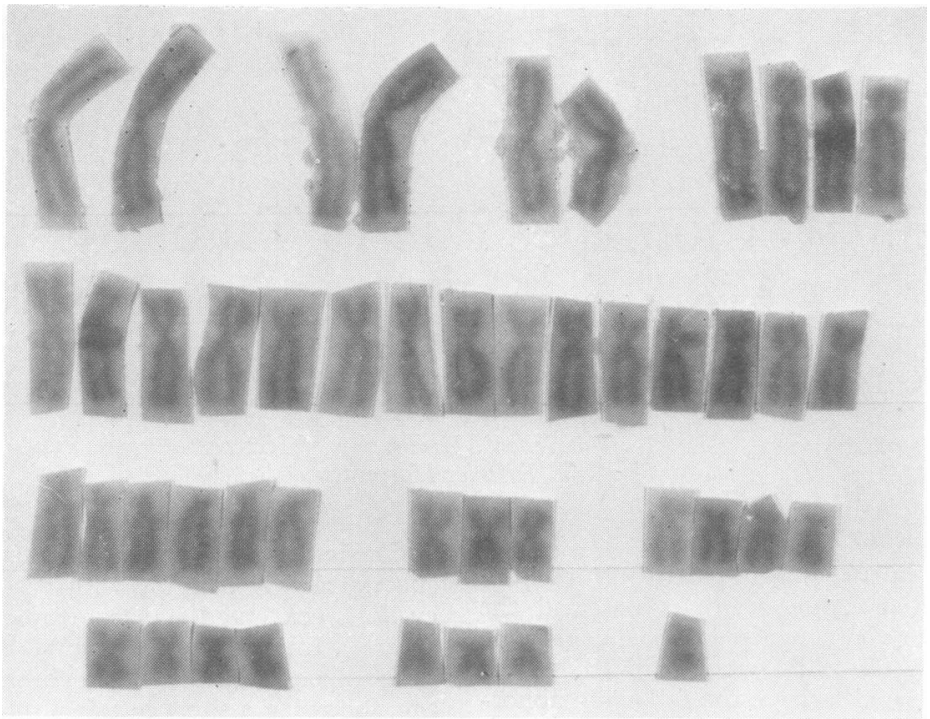

Fig. 3. Karyotype of the propositus.

vessels normally arising from pulmonary trunk and aorta; (iii) a ventricular septal defect measuring about $1 \cdot 5 \mathrm{~cm}$. immediately below the truncus valve ring.

The child weighed I4 lb. (6300 g.) when he died.

Cytological Findings. The karyotype of the propositus is'shown in Fig. 3. There are 46 chromosomes.
There appears to be a member of group $2 \mathrm{I}-22$, not the $Y$, missing, and an extra No. I6 chromosome. The father's chromosomes were normal. The mothess karyotype is shown in Fig. 4. Here again there is a $2 \mathrm{I}-\mathrm{Z}^{2}$ chromosome missing and a 16 chromosome extrat. However the 6-12 group shows one abnormal member with one pair of arms very short.

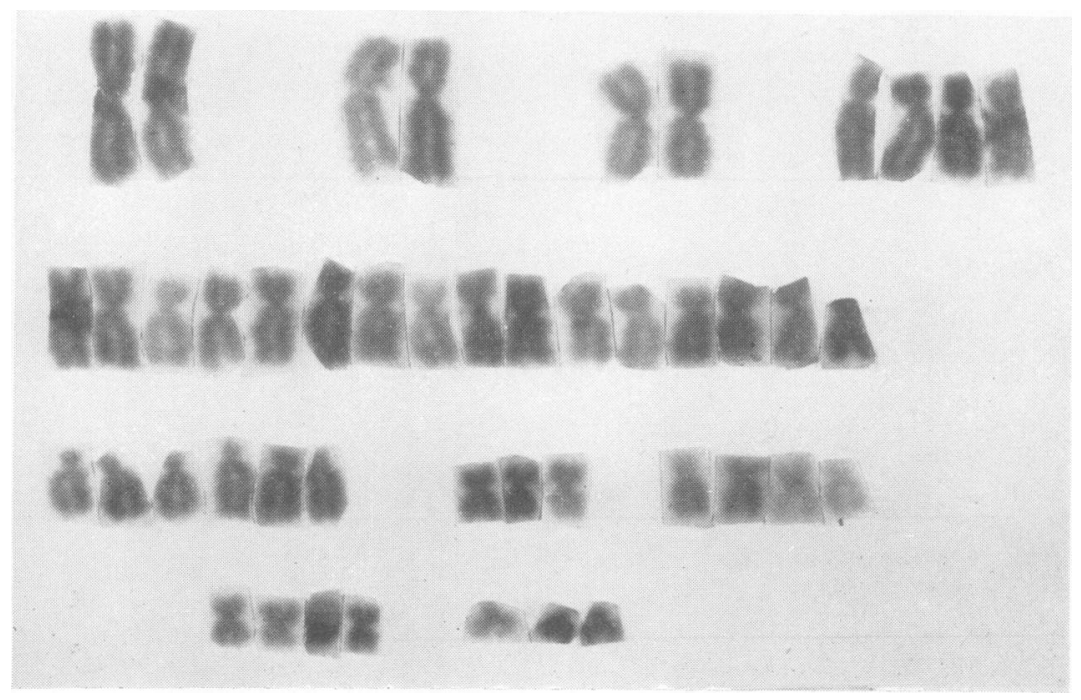

FIG. 4. Karyotype of the mother. 


\section{Discussion}

The simplest explanation of these appearances is to suppose that a translocation has taken place between a small 6-12 and a 2I-22 chromosome in an ancestor of the mother. We suggest that a break has occurred near the centromere in the short arm of both chromosomes. The long arm of the $2 \mathrm{I}-22$ and most of the short arm of the 6-12 have joined to form the abnormal chromosome, similar to a $\mathbf{I} 6$. The remainder of the 6-12 chromosome would then be the abnormal member of that group seen in the mother. In no cells were we able to detect satellites on this chromosome, and this suggests that the short arms of the 2I-22 may have been lost. We know, from the normal carriers of the mongol translocations, that the loss of the short arms of an acrocentric chromosome has no phenotypic effect.

If this interpretation is correct then the mother has lost no important genetic material and has a balanced karyotype. This is supported by her normal phenotype. The child, however, has the normal 6-12 and not the abnormal one produced by the translocation and is, therefore, trisomic for the short arms of one of the smaller 6-12 chromosomes.

The prognosis for further children can be estimated from the types of gametes which one would expect the carrier mother to form. It seems probable that normal gametes and carrier gametes, containing both abnormal chromosomes, would be formed in equal quantities. Two types of abnormal gametes would be formed in quantities equal to each other and probably equal also to the quantities of normal gametes. One type of abnormal gamete would be trisomic for the short arms of the 6-12, as in the propositus, the other type would be monosomic for the short arms of the 6-12. The latter may well be lethal at an early stage, as deficiencies seem usually to be more deleterious than duplications. However, only a relatively small piece of chromosome is involved, and such an embryo might survive long enough to be recognized. The chances for further children seem, therefore, to be equal for normal, carrier, and abnormal children, with a possible rarer chance of a further type of abnormal child. It must be emphasized, however, that meiotic studies have not been done in this family and we are dependent for this body of theory on work done in other species (e.g. Burnham, 1956; Lewis and John, 1963).

A normal birth weight is unusual in cases of autosomal trisomy. In this case we suggest that there was trisomy for only the short arms of one of the smaller 6-12 chromosomes. The parents were advised that there was a risk (perhaps as high as $I$ in 3) of further children being affected but so far they are undecided whether or not to take contraceptive precautions. Because they did not seem to achieve much understanding of the problems involved, we decided not to seek further examples of the translocation in the mother's family.

We thank Dr. C. D. Jobling for the post-mortem report and Mrs. P. Bone of the Department of Photography, University of Newcastle upon Tyne, for the clinical photographs.

\section{REFERENCES}

Burnham, C. R. (1956). Chromosomal interchanges in plants. Bot. Rev., 22, 419.

Lewis, K. R., and John, B. (1963). Spontaneous interchange in chorthippus brunneus. Chromosoma (Berl.), 14, 618. 